\title{
On the Cultivation of University Students' Healthy Social Emotion
}

\author{
Xiangru Jin \\ College of Foreign Languages, Hebei Agricultural University, Baoding, 071001, CHINA \\ Xiaojian Shi \\ College of Humanities and social sciences, Hebei Agricultural University, Baoding, 071001, CHINA
}

Received 15 April 2017 • Revised 31 August 2017 • Accepted 17 September 2017

\begin{abstract}
The cultivation of university students' healthy social emotion is a prerequisite for students to adapt to the new environment of social development, which is conducive to the overall improvement in university students' comprehensive quality. However, study on this subject is insufficient in the current relevant theoretical research which stays in shortcomings analysis, lacking theoretical verification of key means. To further improve the relevant theoretical work, this paper conducts linear regression empirical analysis based on analysis of traditional issues. The conditions influencing cultivation of university students' healthy social emotion was analyzed by regression model, and targeted study was conducted on shaping of students' healthy personality and cultivation of students' moral feelings. The three manifestations of university students' social emotions were then put forward. This paper proposes that efforts should be made to establish targeted cultivation path for university students' healthy social emotion by starting from shaping students' healthy personality and strengthening cultivation of students' moral feelings under the constraints in cultivation conditions of university students' healthy social emotions. In the process of cultivating university students' social emotion, we should integrate humanities education, real social environment, and apply interpersonal communication cultivation method, proceed from shaping students' moral feelings and healthy personality based on the current basic characteristics of university students' social emotion, explore the path to cultivate students' healthy social emotion and ensure healthy development of cultivate students' social emotion.
\end{abstract}

Keywords: university students, social emotion, manifestation, cultivation conditions, cultivation path

\section{INTRODUCTION}

Emotion, as a part of attitude, is consistent with introverted feelings, intentions of attitude as a more complex and stable physiological evaluation and experience of attitude. The so - called social emotion refers to the psychological experience and psychological feelings accompanying the whole social activities of individuals. It belongs to human's high - level emotion which develops from human emotions as a basis and is a unity of emotion and feeling. The human social emotion mainly has two manifestations. The first is the emotional state with a shorter duration, such as excitement, enthusiasm. The other emotional state has a longer duration, such as love, hate, happiness. Healthy social emotion means the state in which individuals can maintain concentration with clear memory, rich association in study, life, work, demonstrating high efficiency in learning and correctly facing life and work. Moreover, individuals in such state have stronger self-control and can correctly evaluate oneself (Beshai, Mcalpine,

(C) Authors. Terms and conditions of Creative Commons Attribution 4.0 International (CC BY 4.0) apply. Correspondence: Xiangru Jin, College of Foreign Languages, Hebei Agricultural University, Baoding, 071001, China, +8615930273189. 


\section{Contribution of this paper to the literature}

- The factors affecting cultivation of university students' healthy social emotion are specified through the linear regression model, vague discussion is avoided.

- Targeted solutions to problems are put forward, with specific opinions given from the practical point of view.

- Under the constraint of model data, the path to cultivate university students' healthy social emotion is given, which makes the way of solving the problem more concrete and practical, and provides the theoretical basis for the next research.

Weare, et al. 2016). During study, life and work, they can correctly face setbacks, keep an open mind, regard study, life and work with positive, optimistic, enterprising attitude. Once unhealthy social emotion appears, poor spirit, low self-esteem, depression, pessimism will occur in work, life, study, which is also accompanied by seclusiveness and defects in emotions, personality, interpersonal relations, leading to incapability to adapt to social development environment. In the university campus, the cultivation of university students' healthy social emotion will help university students better integrate into society and seek sustainable development (Hong, Yang, Song, 2016). Start of university life means that students are no longer a simple "natural person", but a "social person" stepping into society, then simple, ideal emotional world will become extraordinary (Leffel, Mueller, Curlin, et al. 2015).

\section{LITERATURE REVIEW}

In observation of research status quo in this field, relevant scholars have also carried out preliminary study, achieving stage success, but the study is superficial. For instance, Pan Yewang argues that: At present, China's ideological and political education still has immature understanding of university students' emotional education ( $\mathrm{Li}$ 2016; Ma, Qi, et al. 2015). However, only analysis of the problem is given without proposal of specific countermeasures. The relevant literature (Min, Jia, 2017) argues that there are mainly two reasons for cultivation of university students' healthy social emotion as an important part of ideological and political education: first, cultivation of moral emotion and value emotion as the main task of ideological and political education including establishment of interpersonal relationships, students' personality shaping is an important part of moral education. Second, social emotions belong to human's high-level emotions which have an important impact on shaping of university students' healthy personality as an indispensable condition for university students to step into and adapt to society. However, this research only analyses the role of shaping of university students' healthy social emotions in ideological and political education, its role in other educational work is not mentioned (Thein, Guise, Sloan, 2015). Therefore, in the development of higher education, to cultivate university students' healthy social emotion, we should make a discussion on the main manifestations of university students' social emotions in our country, and explore the basic conditions for cultivation of university students' social emotion, and finally establish the healthy social emotion cultivation path integrating humanistic education, real social environment, communicative teaching method (Wang, 2015; Wang, 2016).

\section{METHODS}

\section{Analysis of the Existing Problems}

At present, the social emotion of university students in our country generally has three manifestations of high maturity, idealization and full of passion. Unreasonable control of its development is bound to exert a negative impact on student social development, creating adverse effects on students' social development (Wang, Chai, 2016).

The first is the general increase in maturity. With the continuous broadening of professional knowledge scope of students in contemporary universities, independent analysis ability possessed by students has been further improved, the ability of recognizing right and wrong has also been developed, and their ability to make decisions and solve problems has also been fully cultivated. However, students still have common features of lacking social experience, have insufficient awareness of development law, direction of social things, and have corresponding 
irrationality in emotional expression. There are positive and negative emotions. Positive emotions include selfesteem, curiosity, pleasure, empathy, devotion, etc. which can create a mental state conducive to learning for learners, help learners to realize their potential and enhance their learning outcomes. Negative factors such as anxiety, tension, doubt, depression, etc., will bring learners a bad learning effect (Xiao, Wang, 2017).

The second is idealization. Since the first day of entering the campus, university students' role spontaneously changes. Universities mean half of society, then stepping into campus is equivalent to stepping into society, so students' role is changed from "natural person" to "social person", with social emotions gradually growing. Under the effect of frankness, as students step into the university and have access to ubiquitous communications and contacts, they will inevitably have idealized social emotion, have one-sided understanding towards communication between peoples and between people and society, failing to see that they will soon step into the society. With social emotion in the stage of "natural person", they lack understanding of emotional life from a social point of view (Yang, Sun, 2016).

The third is full of passion. Well-known psychologist Hall held that: university students are in transition from ideological "ignorance stage" to "civilized era". With greater ideological fluctuations, students will "go to extremes" in emotion, ideology, behavior. It can be seen that this stage as the critical period for cultivation of students' correct emotions is also important stage for cultivation of students' healthy social emotion. A slight deviation in ideological guidance will lead to unhealthy social emotion in students (Luo, 2017).

\section{Conditions Influencing Cultivation of University Students' Healthy Social Emotion}

To cultivate students' healthy social emotion in the ideological and political education of universities, we must refer to the present manifestations, establish the basic conditions for cultivation of students' healthy social emotion, proceed from shaping of students' healthy personality and cultivation of students' moral feelings and lay a good foundation for exploration of cultivation path. It is not difficult to find from the main manifestations of university students' social emotion and prerequisite for shaping of university students' healthy social emotion that the path of cultivating students' social emotion should be based on the integration of multiple aspects of humanistic education, real social environment and interpersonal communication cultivation methods, to provide alldirectional impetus to cultivation of students' healthy social emotion.

In this study, the social emotion comprehensive score of the study subjects was selected as the dependent variable $\mathrm{y}$, the personality shaping was selected as $\mathrm{x}_{1}$, the moral feelings cultivation was selected as $\mathrm{x}_{2}$, and the theoretical education $x_{3}$ was selected as the regression item to study the influence of different factors on social emotion cultivation. follows:

In this study applying multiple linear regression model analysis, the specific formula of the model is as

$$
y_{i}=\beta+\alpha_{i} x_{i}
$$

The difference between the estimated value and the actual value is expressed by the residual, and the specific formula is as follows:

$$
\hat{u}_{i}=\hat{y}_{i}-\beta-\alpha_{i} x_{i}
$$

The model regression coefficient is calculated as follows:

$$
R S S=\sum_{i=1}^{N} \hat{u_{i}^{2}}=\sum_{i=1}^{N}\left(y_{i}-\beta-\alpha_{i} x_{i}\right)^{2}
$$

The following results are obtained from this model, as shown in Table 1: 
Jin \& Shi / On the Cultivation of University Students' Healthy Social Emotion

Table 1. Impact of different factors

\begin{tabular}{ccccc}
\hline \multicolumn{5}{c}{ Dependent Variable: $\mathbf{Y}$} \\
\hline Variable & Coefficient & Included observations: $\mathbf{5 0 0}$ & Prob. \\
\hline C & -44.3219 & 0.4532 & 4.5643 & 0.0342 \\
\hline 1 & 3.4324 & 0.4345 & 7.5433 & 0.4324 \\
\hline x2 & 6.5433 & 0.4345 & 4.4545 & 0.2345 \\
\hline x3 & 0.9323 & 0.3456 & 0.4323 & 0.5434 \\
\hline
\end{tabular}

As can be seen from Table 1, the regression term passes the 5\% significance level test, indicating high credibility of the regression results as a whole. The larger regression coefficient indicates the greater influence of regression variable on dependent variable. Hence, it can be seen that shaping of students' healthy personality and cultivation of students' moral feelings have a significant effect on cultivation of social emotion. Both of them have great influence on the final result, while theoretical education factors exert a weak effect on the correlation coefficient.

\section{RESULTS}

\section{Pay Attention to the Shaping of Students' Healthy Personality}

Cultivation of university students' healthy personality concerns development of students' healthy social emotion. Higher education means an important condition for cultivation of healthy social emotions in the shaping of university students' healthy personality. University students are the pillars of future social development, and personality literacy is the necessary inherent quality and conservation for students. This not only affects university students' internal personality, professional ethics after stepping into society and career, but also affects the development trend of market demand for good talent quality. Shaping of good quality of university students is the key to determine their personal qualities, ethics and professional accomplishment (You, Lin, Leung, 2015). Whether students have sound personality concerns whether students can look at and evaluate the development of things from an objective point of view, and affects whether students can deal with people with healthy attitude.

The main methods of shaping include two aspects: First, start from the interpersonal relationship of students, instruct students on the importance of establishing harmonious interpersonal relationships, add interpersonal interaction links in classroom teaching and practical teaching activities, and change students' unhealthy interaction purpose. Second, emphasize the unity of self-consciousness, instruct students to recognize that objective, fair and correct evaluation of their own contributes to their social development, which is also an important factor for people to maintain good communications, interactions (Zhou, Chen, Wu, et al. 2015). Instruct students to deal with people with sincere feelings, view things with peace, tolerance of mind, so as to improve health degree of students' social emotions. Under the action of such conditions, students will change their view to evaluate social development, look at social development, which helps cultivation of students' healthy social emotion.

\section{Strengthen the Cultivation of Students' Moral Feelings}

University students are in the stage of moral conscience generation featuring rich moral feelings. The stage is the most important period for cultivation of students' moral consciousness and moral behavior as healthy moral feelings are gradually shaped. Gradual maturity of students' moral feelings marks the healthy development of students' social emotions (Zhao, Zhang, Du, et al. 2017). Requiring that "ideological and political theory courses should strengthen practice links, establish and improve practice teaching security mechanism and explore longterm mechanism of education through practice." However, the cultivation of university students' healthy social emotion is not just one work content of ideological and political education in universities, but should also be carried out in other educational activities. In strengthening the cultivation of students' moral feelings, we should pay attention to two aspects: First, cultivate students' noble, healthy moral feelings based on campus cultural activities. 
Second, by combining professional practice, give guidance to ideological and moral quality, and cultivate students' healthy social emotions from practical participation. Through cultural activities such as campus literature and art awards competition, campus poetry recitation competition, instruct students to experience inner feelings expressed by others, and optimize students' inner feelings through cultural cultivation. At the same time, with professional practice activities as an important carrier, instruct students to recognize the importance of mutual cooperation, mutual support and mutual promotion with practical activities, which helps cultivation and development of students' healthy social emotions.

\section{DISCUSSION}

\section{Integrate Humanistic Education}

The cultivation of university students' healthy social emotion is an important part of cultivation of qualified talents in higher education. The first step in building the path for cultivating university students' healthy social emotions is to integrate humanistic education. Humanities education plays an important role in modern higher education. The colorful activities will trigger students' thinking, so that they dare to take responsibility and have the courage to act, cultivating their healthy social emotion and training talents with lifelong learning ability and humanistic spirit for sustainable development of society. Whether it is in ideological and political education or other educational activities, teachers' classroom teaching easily ignores cultivation of humanistic spirit, ignores students' emotional needs and value guidance (Ma, Qi, et al. 2015). With the continuously quickening social development process, university students' own social values have also been affected. The idea of realizing self social value in the infancy stage of adolescence cannot adapt to social development trend, and the maximization of self - interest becomes the core of values. It is generation of this idea that leads to gradual appearance of students' unhealthy social emotions, with purposeful struggle, mutual use, psychological divisive tactics deteriorating and unhealthy social emotions prevailing in the majority of university students. Considering this situation, cultivation of students' healthy social emotions in higher education should be coordinated based on humanities education. It should instruct students to establish a stable social mentality through guidance of excellent humanistic spirit and traditional culture, and then look at social emotion in a responsible mind.

Therefore, in the work of higher education, the method of integrating humanistic education can be explored from two perspectives: First, introduce Chinese traditional culture related contents, nurture students' awareness of self-social responsibility to promote cultivation of students' healthy social emotion. Second, view socialist core values as important content of higher education, take courtesy, integrity, friendliness as the main educational contents, cultivate students' healthy and optimistic social feelings, and optimize students' social emotion. Introduce social responsibility, social morality in traditional Chinese culture, instruct students to correctly understand the relationship between social emotional input and social returns, change their original self interestcentered value concept, and upgrade students' social moral quality. The cultivation and development of sense of social responsibility is a process of gradual accumulation, continuous transformation or reorganization, which has its own law of development. The individual psychology, self - consciousness, thinking level, moral judgment and choice of university students have been matured, but as they are in the active period of value formation, it is necessary to strengthen the education of sense of social responsibility of university students. The connotation of the socialist core values should be widely disseminated in the ideological and political education so that students can realize the importance of social mentality of courtesy, integrity, harmony and friendliness, which can promote emergence of ideology of treating others sincerely, being courteous and sincere cooperation, and help cultivate healthy social emotions.

\section{Integrate Real Social Environment}

In the main task of cultivating talents in higher education, extensive cultivation of talents with healthy thinking and good quality should be regarded as the core task, while cultivation of healthy social emotion should be treated as an important content. At present, most university students in our country are the only children with obvious "self-centered" thinking and very serious egoistic psychology who lack cooperation, communication with 
others, have poor social communication ability and less cultivated social emotions. In the process of cultivating healthy social emotion of university students, the real social environment should be integrated into the education work in various fields, so that students establish "group-centered" thinking through cultivation by social environment, enhance consciousness of cooperation and exchange with others and promote the cultivation of healthy social emotions.

The main fusion path includes two aspects: First, carry out social practice education activities, cultivate students' social sentiment through high quality cultural life, change students' simple view towards society, instruct students to recognize the temperament necessary for the fierce social competition, upgrading students' inner world. Second, integrate community activities into the higher education system, cultivate university students' team awareness through community activities, and shape university students' enterprising sprit of unremitting struggle, thus controlling the development of their negative emotions. This is an important part of cultivation path construction of university students' healthy social emotion, also the prerequisite for the application of interpersonal communication cultivation method.

\section{Use Interpersonal Communication Cultivation Method}

The cultivation of university students' healthy social emotion emphasizes the cultivation of students' selfcontrol to prevent the random development of unhealthy emotions. Whether it is in ideological and political education activities or other educational activities, interpersonal communication cultivation method should be the most important. The social adaptability of university students concerns harmonious development of society and personal development of students. In social transformation, some students have problems to adapt to study, work, psychology, interpersonal communication, etc. The so-called interpersonal communication cultivation method is to instruct students to carry out exchange between people through practical activities, instruct them to establish correct concept of interpersonal communication with the real society as the background, ensure that students look at interpersonal relationships with positive, peaceful and optimistic attitude to achieve the purpose of easy selfemotional control. Where, organization of related exchange activities with community activities, professional practice activities and social welfare activities as the main carrier to express each other's inner feelings and ideas is conducive to cultivation of university students' healthy social emotion. In addition, the use of interpersonal communication cultivation method needs not only feelings but also rationality. Tagore once said that in the process of interpersonal communication, first moving others' heart is a must to arouse people's rational thinking towards interpersonal relationship. In the use of emotional communication cultivation method, we must improve infectivity of the cultivation process, mobilize students' feelings while cultivating their mind, so that students experience interpersonal relationships from the heart with healthy personality shaped, thus able to adapt to various social roles in their posts.

\section{CONCLUSION}

In the work of higher education, the cultivation of university students' healthy social emotion concerns whether students can adapt to the needs of society and affects the comprehensive development of students' overall quality. Students' entry into the university campus marks entry into the society with "one foot". Their emotion should not stay in the middle school stage, as they need respect the objective facts in dealing with things and people, get rid of naive, ideal inner thoughts, face study and life with unity, cooperation, mutual promotion in mind. Therefore, in the process of cultivating university students' social emotion, we should start from shaping students' moral feelings and healthy personality based on basic characteristics of university students' social emotion, explore the path to cultivate students' healthy social emotion to ensure healthy development of university students' social emotion. 


\section{REFERENCES}

Beshai, S., Mcalpine, L., Weare, K., \& Kuyken, W. (2016). A Non-Randomised Feasibility Trial Assessing the Efficacy of a Mindfulness-Based Intervention for Teachers to Reduce Stress and Improve Well-Being. Mindfulness, 7, 198-208.

Hong, J., Yang, Y., \& Song, G. (2016). A theory of creative expressiveness: empirical studies in Chinese universities. Chinese Management Studies, 10, 387-404.

Leffel, G. M., Mueller, R. A. O., Curlin, F. A., Yoon, J. D. (2015). Relevance of the rationalist-intuitionist debate for ethics and professionalism in medical education. Advances in Health Sciences Education, 20, 1371-1383.

Li, R. (2016). Strategies to enhance the intercultural communication competence of college students' cognition level. Research of heilongjiang high education, 12, 145-147.

Luo, S. M. (2017). Foreign Relations in Sports as a Discipline. Journal of Nanjing Sport Institute (Social Science), 30, 16.

Ma, G. S., Qi, J. Z., et al. (2015). The research and practice of comprehensive quality training system for college students with the characteristics of "benevolence and wisdom". Chinese professional technology education, $10,38-42$.

Min, C. C., \& Jia, X. M. (2017). On the guidance of counselors on social emotions of college students. Research of heilongjiang high education, 3, 130-132.

Thein, A. H., Guise, M., \& Sloan, D. A. L. (2015). Examining Emotional Rules in the English Classroom: A Critical Discourse Analysis of One Student's Literary Responses in Two Academic Contexts. Research in the Teaching of English, 49, 200-223.

Wang, S. (2015). How to guide college students to complete the change of social role - talk about the significance of performance training in university education. Research of heilongjiang high education, 6, 155-158.

Wang, X. H., \& Chai, M. M. (2016). The survey and analysis of social psychology of college students in Tibet under the network environment. Chinese professional technology education, 1, 203-205.

Wang, X. L. (2016). The construction of contemporary college students' management ethics under the governance paradigm. Research of heilongjiang high education, 8, 36-39.

Xiao, H. X., \& Wang, W. P. (2017). Deconstruction and construction: the gender difference of college students' vocational ability and their genetic analysis. Chinese professional technology education, 9, 24-29.

Yang, Y., \& Sun, S. P. (2016). The strategy of higher vocational college students' employment ability based on human capital theory. Chinese professional technology education, 6, 5-9.

You, J., Lin, M. P., \& Leung, F. A. (2015). Longitudinal Moderated Mediation Model of Nonsuicidal Self-injury among Adolescents. Journal of Abnormal Child Psychology, 43, 381-390.

Zhao, J. F., Zhang, S. C., Du, Y. L., et al. (2017). College students feel the need to understand the relationship between social support and cell phone addiction. School health in China, 9, 876-878.

Zhou, X., Chen, Q., Wu, J., et al. (2015). To expand training to improve the mental health level and social adaptability of middle school students. Chinese professional technology education, 36, 245-247.

\section{http://www.ejmste.com}

